\title{
Seasonal Metal Distribution in Ondo Coastal Sediment, Nigeria
}

\author{
${ }^{1}$ OLOLADE I.A,; ${ }^{2}$ LAJIDE, L.; ${ }^{2}$ AMOO, I.A \\ ${ }^{I}$ Department of Chemistry and Industrial Chemistry, Adekunle Ajasin University, Akungba-Akoko, Ondo-State, Nigeria. \\ ${ }^{2}$ Department of Chemistry, Federal University of Technology, Akure, Nigeria. \\ Correspondent author: Ololade I.A. E-mail: Olisa200@yahoo.com.
}

\begin{abstract}
The distribution of heavy metals in streambed sediment from an oil-producing region in Nigeria has been examined between the two distinct seasons (dry and wet). The highest mean concentration during the dry season (wet season in brackets) was $2083.37355 .5(2264.2 ア 347.3) \mathrm{mg} / \mathrm{kg} \mathrm{Cu}$ and $0.16 \curlyvee 0.06$ $(0.19$ \% 0.09$) \mathrm{mg} / \mathrm{kg} \mathrm{Zn}$ respectively. With similar patterns at both seasons, the order of increasing concentration was $\mathrm{Zn}<\mathrm{Cd}<\mathrm{Ni}<\mathrm{Pb}<<\mathrm{Cu}$. Apart from $\mathrm{Pb}$, metal concentration occurred at greater concentrations during the wet season. Elevated concentration of $\mathrm{Cu}$ in the study was attributable to the nature of Nigerian soil. However, the impact of oil related activities within the study r egion may be contributing to the levels of other metals, particularly $\mathrm{Pb}$. Significant correlations $(\mathrm{r}=0.05 ; 0.01)$ were record ed between some of the metals, $\mathrm{pH}$ and \%clay in the mud fraction. Cadmium vs $\mathrm{Ni}$ and $\mathrm{Cu}$ vs $\mathrm{Ni}$ were both significant at both seasons. The clay fraction of the mud were significantly correlated with $\mathrm{Pb}(\mathrm{r}=0.949), \mathrm{Cd}(\mathrm{r}=0.749)$ ad $\mathrm{Ni}(\mathrm{r}=0.869)$. The partition coefficient data showed that several $\mathrm{f}$ actors controlled the adsorption of metals unto the sediment. Comparison of sediment with guideline values indicated anthropogenic enrichment but it was considered that only $\mathrm{Cu}$, and possibly $\mathrm{Pb}$ pose potential threats to the ecology of the area. @ JASEM
\end{abstract}

In the recent years, there has been increasing concern by communities and concerned individual over the pollution of the marine environment, especially relating to the presence of anthropogenic contaminants and their possible biological effects. Not until 1996 when the first oil spill tagged 'YAYE' Oil Spill occurred within the coastal area of Ondo State, Nigeria, the ocean was considered generally free of contaminants. The delay in this study for metal input into the aquatic environment was born out of the fact that levels of metals in oil are considered very small. Thus, it is envisaged that possible and significant accumulation may have occurred over the years and which may now require urgent attention.

Heavy metals, such as cadmium, mercury, lead, copper nickel and zinc, are regarded as serious pollutants of aquatic ecosystems because of their environmental persistence, toxicity and ability to be incorporated into the food chains. Several investigations have been reported in the in the literatures on the concentration and partitioning of these metals in sediment. Some of these studies are based on the fact that the aquatic environment has been regarded as a dumping site especially in most developing countries. This indiscriminate dumping, in some cases, has led to serious health problems to animals and humans via ingestion of soil and/or sediment, seafood's and water. The toxicity of most of these metals has been attributed mainly to capability of the ions to form stable complexes with the active sites of protein. Factors such as $\mathrm{pH}$, redox potential, and total organic carbon and cation exchange capacity (CEC) have been identified as some of the major factors controlling the levels of metals in the river system.
Little environmental data is available for the coastal region of Ondo State located within the southwestern region of Nigeria. The sampling sites are locations that are noted for large biological production and are especially important for commercial fish. The dominant potential source of contaminants is presumably the ongoing petroleum related activities. Consequently; the present report is on the analysis of a suite of trace metals ( $\mathrm{Cd}, \mathrm{Cu}, \mathrm{Pb}, \mathrm{Ni}$ and $\mathrm{Zn}$ ). These along with $\mathrm{Hg}$ (not determined in this study) may be considered the most biological significant metals.

\section{MATERIALS AND METHODS Sample Collection and Preparation}

Streambed sediments were sampled during the dry and wet seasons of 2005. Seven sampling sites were examined along with one reference location. The samples were collected at each site, one from midstream and one from each bank in a cross section fashion. About five locations were considered at each sampling site. Samples from each location were homogenized into a composite sample from which representative samples were taken. Details of the samples locations and site identification coordinates as revealed by global positioning system (GPS) are presented in Table 1.The mud fraction of the sediment, consisting of the silt plus clay sizes $(<63 \mu \mathrm{m})$ were used for metal analysis. With this fraction, the effect of varying granulometry on the trace metal contents between the samples was minimized ${ }^{13}$. Moreover, in this fraction which is generally enriched in clay minerals and organics, the particle-reactive metals are expected to be concentrated by ion ex change, adsorption and clay-metal-organic complex formation. In fact, this fraction remains the most 
desirable sediment component for monitoring metal pollution.

This fraction (mud) was obtained by suspending a $5 \mathrm{~g}$ of a thawed grab subsample in deionized distilled water and homogenized. The suspension was sieved through a 230-mesh nylon screen, and the separated mud particles were then freezedried and powdered using an agate mortar and pestle. This process of mud separation by wet sieving may possibly results in hydrolysis of some metals or desorption from the sediment which may lead to loss of metal portions. This portion is considered negligible.

\section{Chemical Analysis}

A $0.5 \mathrm{~g}$ aliquot of the dried powder was taken into a $140 \mathrm{ml}$ Teflon bomb and digested in $15 \mathrm{ml}$ of a high purity concentrated $7 \mathrm{ml}-\mathrm{HF}+5 \mathrm{ml}-$ $\mathrm{HNO}_{3}+3 \mathrm{ml}-\mathrm{HCl}$ acid mixture on a hot plate at about $1100 \mathrm{C}$ for 6 hours within a fume cupboard. After cooling to room temperature, the digest was diluted to $100 \mathrm{ml}$ and dried and then again dissolved in $10 \% \mathrm{HNO}_{3}$ and made up to $20 \mathrm{ml}$ by adding deionized water. From the final solution, $\mathrm{C} \mathrm{d}, \mathrm{Cu}, \mathrm{Pb}, \mathrm{Ni}$ and $\mathrm{Zn}$ were analysed using atomic absorption spectrophotometer (Alpha 4AAS, Chemical Tech. Analytical Euro). The pH (1:2.5 sediment: water) and electrical conductivity (EC) were measured using Hanna $\mathrm{pH} 211$ microprocessor $\mathrm{pH}$ meter and $\mathrm{EC}$ meter (expressed in $\mathrm{mS} \mathrm{cm}{ }^{-1}$ at 250C) respectively. Total organic carbon (TOC) and the CEC were analysed based on literature. Carbonate in the samples was measured by acid neutralization method as reported in literature.

Quality assurance (QA)/ control (QC) protocol prescribed by the U. S Environmental Protection Agency (EPA) for metal analysis was used. In this study, analytical precision through replicate runs and the use of certified standard reference material PACS-2 (heavily contaminated marine sediment available from the Natural Research Council, Canada) was employed. The results are shown in Table 2. The percent recoveries are quite reasonable.

\section{Statistical Analysis}

We performed statistical analysis by combining data from the two seasons. Statistical differences in season al metals level were determined by one-way ANOVA, followed by Duncan new multiple range test Relationships between metals and other controlling factors era determined $\mathrm{b} y$ bivariate correlation using the Pearson coefficient in a two-tailed test $(\mathrm{r}=0.01$ and 0.05$)$. All analysis was performed using SPSS software (version 13.0).

\section{RESULTS}

Details of the $\mathrm{pH}, \mathrm{EC}, \mathrm{TOC}$ and CEC with percent clay in the individual sediment samples are included in Table 1. Table 3 shows the mean concentration (dry and wet seasons) of the trace metal in the mud fraction $(<63$ t $\mathrm{m}$ size) of the sediments. The mean concentration of $\mathrm{Cd}$ at location $\mathrm{S}_{6}$ was the highest $(2.53 \mathrm{mg} / \mathrm{kg})$ and that from location $\mathrm{S}_{4}$ during the dry season was the least $(0.75 \mathrm{mg} / \mathrm{kg})$. The concentration of $\mathrm{Cu}$ at location $\mathrm{S}_{2}$ was the highest during the wet season $(2616.8 \mathrm{mg} / \mathrm{kg})$ while $1862.4 \mathrm{mg} / \mathrm{kg} \mathrm{Cu}$ was the least recorded at site $\mathrm{S}_{5}$ during the dry season. Highest and least mean concentrations of $42.8 \mathrm{mg} / \mathrm{kg}$ and $11.3 \mathrm{mg} / \mathrm{kg}$ of $\mathrm{Pb}$ were recorded at $\mathrm{S}_{6}$ and $\mathrm{S}_{3}$ during the dry and wet season respectively. For $\mathrm{Ni}$, highest and least values of $8.3 \mathrm{mg} / \mathrm{kg}$ and $3.1 \mathrm{mg} . \mathrm{kg}$ were recorded respectively at $S_{6}$ and $S_{3}$ sediments both during the wet season. Zinc, which was generally recorded at lowest concentration compared to other metals was at the highest and least concentrations $(0.28 \mathrm{mg} / \mathrm{kg})$ and $(0.02 \mathrm{mg} / \mathrm{kg})$ at $\mathrm{S} 6$ and S2 during the wet and dry seasons respectively. The results in Table 1 displayed significant seasonal variation in the metal levels which can be judged to be regular across the entire studied area. In fact, a similar pattern of increasing concentrations at both season was observed to follow the order $\mathrm{Zn}<\mathrm{Cd}<\mathrm{Ni}<\mathrm{Pb}<<\mathrm{Cu}$ and apart from $\mathrm{Pb}$, higher concentrations of other metals were recorded during the wet season.

Table 1. Sample Locations and some Sediment Characterization ${ }^{\#}$

\begin{tabular}{lccccccc}
\hline Locations & Latitude(N) & Longitude(W) & pH & \% Clay & OC & CEC & CaCO $_{3}$ Equiv. \\
\hline Ayetoro & $06^{0} 06^{\prime} 12.4^{\prime \prime}$ & $004^{0} 46^{\prime} 36.0^{\prime \prime}$ & 6.6 & 15.4 & 9.34 & 96.15 & 18.6 \\
Ilepete & $06^{0} 02^{\prime} 10.0^{\prime \prime}$ & $004^{0} 51^{\prime} 23.3^{\prime \prime}$ & 6.3 & 15.2 & 7.86 & 98.81 & 16.4 \\
Obe-Nla & $06^{0} 00^{\prime} 51.9^{\prime \prime}$ & $004^{0} 52^{\prime} 40.2^{\prime \prime}$ & 6.3 & 15.9 & 9.95 & 124.15 & 16.1 \\
Ikorigho & $05^{0} 57^{\prime} 15.0^{\prime \prime}$ & $004^{0} 53^{\prime} 59.6^{\prime \prime}$ & 5.9 & 18.1 & 9.36 & 107.35 & 13.4 \\
Ojumole & $05^{0} 56^{\prime} 05.4^{\prime \prime}$ & $004^{0} 53^{\prime} 10.2^{\prime \prime}$ & 6.9 & 20.1 & 9.22 & 103.71 & 19.2 \\
Otumara & $05^{0} 56^{\prime} 42.8^{\prime \prime}$ & $004^{0} 55^{\prime} 55.8^{\prime \prime}$ & 6.1 & 22.4 & 9.66 & 115.91 & 14.9 \\
Awoye & $05^{0} 54^{\prime} 46.7^{\prime \prime}$ & $004^{0} 57^{\prime} 56.2^{\prime \prime}$ & 6.1 & 18.7 & 11.5 & 125.11 & 14.5 \\
\hline Igbokoda* & $06^{0} 09^{\prime} 12.7^{\prime \prime}$ & $004^{0} 44^{\prime} 32.5^{\prime \prime}$ & 5.6 & 10.5 & 12.7 & 219.25 & 10.4 \\
\hline
\end{tabular}

\# Values are mean of the two seasons

- Reference location

* Corresponding author: ${ }^{1}$ Ololade I.A. 


\section{DISCUSSION}

The results of sediment characterization test (Table 1) showed that the seasonal $\mathrm{pH}$ values ranges from $5.9-6.9$. This is reflective of slightly acidic environment, though still quite tolerable to most aquatic organisms. The EC ranges between $0.826-0.880 \mathrm{mS} \mathrm{cm}^{-1}$ while the TOC levels in the sediment were very high, ranging from $7 \%$ to $87 \%$ based on data on soil guidelines which are expected to be $<3.0 \%$. This indicates large amount of detritus in the sediment which may be due to poor microbial degradation. The average CEC for both seasons are generally high ranging from 96.15 - 124.15 (meq/100g). This range is considered to be far above the EPA's guidelines for CEC. Moreover, the high CEC values indicate the presence of more clay and OC. Seasonal average values of $\mathrm{CaCO}_{3}$ equivalent (in \%) ranges from 13.34 -19.2. This range indicated the dominance of carbonate minerals in Ondo coastal sediment. Correlations among the metals concentrations, $\mathrm{pH}$ and $\mathrm{OC}$ content were determined. For both seasons, significant variability in both metal and OC concentration among individual sediment samples appears to be related to the portion of mud fraction found in each sample. Using the entire data set obtained during the study, significant correlations $(=0.05 ; 0.01)$ were recorded between some of the metals, $\mathrm{pH}$ and \%clay in the mud fraction (Table 4). Cadmium vs $\mathrm{Ni}$ and $\mathrm{Cu}$ vs $\mathrm{Ni}$ were both significant at both seasons. $\mathrm{pH}$ only showed significant correlation with $\mathrm{Cd}(\mathrm{r}=$ 0.813) while the clay fraction of the mud were significantly correlated with $\mathrm{Pb}(\mathrm{r}=0.949), \mathrm{Cd}(\mathrm{r}=$ $0.749)$ ad $\mathrm{Ni}(\mathrm{r}=0.869)$. No significant correlations were found between $\mathrm{Pb}$ vs $\mathrm{Cd}$ and $\mathrm{Cu}$ and $\mathrm{Pb}$. This lack of correlation showed that the metals are likely sourced differently. Most of the metals are negatively correlated with the CEC. This is of great concern as increased levels of these metals in the environment consequently results in decreased mineral element composition of the sediment. Thus, the nutritional value of sediment as food source to aquatic biota is reduced. It is interesting, moreover, to note that the metals are negatively correlated to percentage $\mathrm{OC}$ in the sediment. These negative correlations suggest that the metals are associated with a coarser type of particle.

Clearly, visible seasonal changes in the concentration of the metals were observed where, except for $\mathrm{Pb}$, the concentrations of other metals are higher during the wet season. The characteristic nature of the dry season sampling such as oil spillage which occurred few weeks before sample collection may be attributed to the level of lead obtained during this period. Comparing metal concentrations in the study with other related studies showed that except for $\mathrm{Cu}$, levels of the metals are far less than those obtained in the Hecken Sack River and Newark Bay, which were $10 ア 6 \mathrm{mg} / \mathrm{kg} \mathrm{Cd} ; 237 \uparrow 222 \mathrm{mg} / \mathrm{kg}$ $\mathrm{C}$ u. $421>571 \mathrm{mg} / \mathrm{kg} \mathrm{Pb}, 39 \uparrow 49 \mathrm{mg} / \mathrm{kg} \mathrm{Ni}$ and $395749 \mathrm{mg} / \mathrm{kg} \mathrm{Zn}$. Metals concentrations in the study were also compared with other studies considered to represents deposits influenced by petroleum related industrial activities. There are significantly higher $(\mathrm{p}<0.05)$ mean concentrations of $\mathrm{Cd}, \mathrm{Pb}$ and $\mathrm{Cu}$ in mud samples of the sediments in the study than in mud of the near shore of the petroleum related industrial area of Colville Delta - Budhoe Bay region. The reason for these differences is uncertain. Some of the possible factors contributing to this disparity are relatively higher input of the metals into Ondo coastal area from confined terrestrial sources, anthropogenic input in the form of oil spill (oil contains some levels of metals) and this may further implicate, in particular that leaded gasoline has not totally been phased out in our petroleum products. In addition, the variation may results from regional differences in mass sediment accumulation rates. Alternatively, a relatively higher atmospheric deposition of anthropogenic metals may equally results in regional differences in sediment metal concentration. It has been shown that relatively higher concentrations of $\mathrm{Ni}$ and several other metals exists in freshly precipitated snow and that snow is a significant medium for sequestering and entraining atmospheric-borne metals with subsequent co-precipitation in the lagoon. It is therefore possible that over the year's higher metals fluxes tied to the depositional snow result in greater concentrations of metals in the mud of Ondo streambed sediment. Moreover, runoff activities and contaminants from land based sources introduced into the surface waters may rapidly become scavenged by suspended particles that tend to settle to the bottom where they become highly concentrated. This may be responsible for the increased level of some metals in this report. This is also in agreement with other study.

* Corresponding author: ${ }^{1}$ Ololade I.A. 
Table 2. Results of QA/QC analysis (Trace Metals ( $\mathrm{mg} / \mathrm{kg}$ ) dry weight basis)

\begin{tabular}{cccccc}
\hline Sample & $\mathbf{C d}$ & $\mathbf{C u}$ & $\mathbf{P b}$ & $\mathbf{N i}$ & $\mathbf{Z n}$ \\
\hline Blank-1 & -0.001 & 0.000 & 0.012 & 0.02 & -0.11 \\
Blank-2 & 0.001 & 0.001 & 0.017 & 0.05 & -0.09 \\
Blank-3 & -0.001 & 0.000 & 0.015 & 0.04 & -0.14 \\
Mean & -0.001 & $<0.001$ & 0.015 & 0.04 & -0.11 \\
Estimated MDL & 0.002 & 0.001 & 0.004 & 0.05 & 0.006 \\
SRM & & & & & \\
True value & NI & 310 & 183 & 39.5 & 364 \\
\hline Recovery & - & 317 & 163.4 & 31.4 & 379
\end{tabular}

$M D L=$ Method Detection Limit $S R M=$ Standard Reference Material. $I=$ Not Indicated. $a=$ Mean of Duplicate Analysis

Table 3. Trace Metals Concentration ${ }^{\#}(\mathrm{mg} / \mathrm{kg}$ dry weight) Sediments of Ondo Coastal River, Nigeria

\begin{tabular}{|c|c|c|c|c|c|c|}
\hline \multicolumn{2}{|l|}{ Locations } & Cd & $\mathrm{Cu}$ & $\mathbf{P b}$ & $\mathbf{N i}$ & Zn \\
\hline \multicolumn{2}{|l|}{ Ayetoro } & $1.92^{\mathrm{b}} \pm 1.2$ & $\begin{array}{c}2104.5^{\mathrm{g}} \pm 2.1 \\
\left(21992^{\mathrm{e}}+14\right.\end{array}$ & $\begin{array}{l}11.9^{\mathrm{e}} \pm 0.5 \\
\left(93^{\mathrm{b}}+0.9\right)\end{array}$ & $\begin{array}{l}4.9^{\mathrm{d}} \pm 1.5 \\
\left(57^{\mathrm{b}}+1\right.\end{array}$ & $\begin{array}{c}0.28^{\mathrm{a}} \pm 1.10 \\
\left(034^{\mathrm{a}}+1.04\right)\end{array}$ \\
\hline \multicolumn{2}{|l|}{ Ilepete } & $\begin{array}{c}1.07^{\mathrm{b}} \pm 0.75 \\
\left(1.87^{\mathrm{b}} \pm 1.05\right)\end{array}$ & $\begin{aligned} 2566.7^{\mathrm{c}} & \pm 6.4 \\
\left(2616.8^{\mathrm{h}}\right. & \pm 1.9)\end{aligned}$ & $\begin{array}{c}9.2^{\mathrm{b}} \pm 0.1 \\
\left(11.3^{\mathrm{e}} \pm 2.3\right)\end{array}$ & $\begin{array}{l}4.4^{\mathrm{a} \cdot \mathrm{b}} \pm 2.1 \\
\left(6.1^{\mathrm{d}} \pm 2.3\right)\end{array}$ & $\begin{array}{c}0.20^{\mathrm{a}} \pm 0.02 \\
\left(0.13^{\mathrm{a}} \pm 0.14\right)\end{array}$ \\
\hline \multicolumn{2}{|l|}{ Obe Nla } & $\begin{array}{c}1.85^{\mathrm{b}} \pm 0.13 \\
\left(1.91^{\mathrm{b}} \pm 2.09\right)\end{array}$ & $\begin{array}{c}2004.2^{\mathrm{h}} \pm 0.4 \\
\left(2286.1^{\mathrm{h}} \pm 2.1\right)\end{array}$ & $\begin{array}{c}16.1^{\mathrm{e}} \pm 0.1 \\
\left.12.2^{\mathrm{e}} \pm 2.1\right)\end{array}$ & $\begin{array}{c}4.8^{\mathrm{d}} \pm 1.5 \\
\left(6.3^{\mathrm{d}} \pm 1.9\right)\end{array}$ & $\begin{array}{c}0.14^{\mathrm{a}} \pm 0.01 \\
\left(0.21^{\mathrm{a}} \pm 0.09\right)\end{array}$ \\
\hline \multicolumn{2}{|l|}{ Ikorigbo } & $\begin{array}{c}0.75^{\mathrm{a}} \pm 0.14 \\
\left(1.12^{\mathrm{b}} \pm 1.05\right)\end{array}$ & $\begin{array}{c}2025.3^{\mathrm{d}} \pm 1.5 \\
\left(2341.3^{\mathrm{h}} \pm 1.4\right)\end{array}$ & $\begin{array}{c}19.9^{\mathrm{e}} \pm 1.0 \\
\left(13.4^{\mathrm{e}} \pm 0.6\right)\end{array}$ & $\begin{array}{c}3.1^{\mathrm{a}} \pm 1.6 \\
\left(5.1^{\mathrm{d}} \pm 2.6\right)\end{array}$ & $\begin{array}{c}0.12^{\mathrm{a}} \pm 0.10 \\
\left(0.19^{\mathrm{a}} \pm 0.32\right)\end{array}$ \\
\hline \multicolumn{2}{|l|}{ Ojumole } & $\begin{array}{c}2.34^{\mathrm{b}} \pm 0.38 \\
\left(2.52^{\mathrm{b}} \pm 0.14\right)\end{array}$ & $\begin{array}{c}1862.4^{\mathrm{g}} \pm 3.6 \\
\left(1895.8^{\mathrm{g}} \pm 6.1\right)\end{array}$ & $\begin{array}{c}20.8^{\mathrm{d}} \pm 0.4 \\
\left(15.2^{\mathrm{d}} \pm 0.3\right)\end{array}$ & $\begin{array}{c}4.4^{\mathrm{e}} \pm 0.3 \\
\left(6.4^{\mathrm{e}} \pm 0.3\right)\end{array}$ & $\begin{array}{c}0.15^{\mathrm{a}} \pm 0.10 \\
\left(0.17^{\mathrm{a}} \pm 0.36\right)\end{array}$ \\
\hline \multicolumn{2}{|l|}{ Otumara } & $\begin{array}{c}2.03^{\mathrm{b}} \pm 1.10 \\
\left(2.53^{\mathrm{b}} \pm 0.81\right)\end{array}$ & $\begin{array}{c}2499.3^{\mathrm{h}} \pm 0.3 \\
\left(2613.9^{\mathrm{f}} \pm 3.6\right)\end{array}$ & $\begin{array}{c}42.8^{\mathrm{f}} \pm 0.1 \\
\left(22.3^{\mathrm{f}} \pm 0.9\right)\end{array}$ & $\begin{array}{c}5.9^{\mathrm{d}} \pm 1.3 \\
\left(8.3^{\mathrm{c}} \pm 1.4\right)\end{array}$ & $\begin{array}{c}0.20^{\mathrm{a}} \pm 1.23 \\
\left(0.24^{\mathrm{a}} \pm 0.24\right)\end{array}$ \\
\hline \multicolumn{2}{|l|}{ Awoye } & $\begin{array}{c}1.58^{\mathrm{b}} \pm 0.61 \\
\left(1.66^{\mathrm{b}} \pm 1.04\right)\end{array}$ & $\begin{array}{c}2162.5^{\mathrm{f}} \pm 1.2 \\
\left(2519.6^{\mathrm{g}} \pm 1.9\right)\end{array}$ & $\begin{array}{c}21.0^{\mathrm{d}} \pm 0.3 \\
\left(19.1^{\mathrm{e}} \pm 1.8\right)\end{array}$ & $\begin{array}{c}3.8^{\mathrm{e}} \pm 1.2 \\
\left(6.6^{\mathrm{d}} \pm 1.3\right)\end{array}$ & $\begin{array}{c}0.02^{\mathrm{a}} \pm 0.01 \\
\left(0.16^{\mathrm{a}} \pm 0.50\right)\end{array}$ \\
\hline \multicolumn{2}{|l|}{ Igbokoda* } & $\begin{array}{c}1.27^{\mathrm{b}} \pm 0.19 \\
\left(0.82^{\mathrm{b}} \pm 1.26\right)\end{array}$ & $\begin{array}{c}1441.1^{\mathrm{f}} \pm 1.15 \\
\left(1643.3^{\mathrm{g}} \pm 1.7\right)\end{array}$ & $\begin{array}{l}14.3^{\mathrm{a}} \pm 0.6 \\
\left(9.2^{\mathrm{e}} \pm 0.5\right)\end{array}$ & $\begin{array}{c}1.3^{\mathrm{b}} \pm 0.4 \\
\left(2.5^{\mathrm{d}} \pm 0.7\right)\end{array}$ & $\begin{array}{c}0.27^{\mathrm{a}} \pm 0.58 \\
\left(0.04^{\mathrm{a}} \pm 0.01\right)\end{array}$ \\
\hline Mean \pm S.D & $\begin{array}{l}\text { Dry } \\
\text { Wet }\end{array}$ & $\begin{array}{l}1.60 \pm 0.67 \\
1.75 \pm 0.75\end{array}$ & $\begin{array}{l}2083.3 \pm 355.5 \\
2264.4 \pm 347.1\end{array}$ & $\begin{array}{c}18.3 \pm 11.7 \\
13.2 \pm 5.9\end{array}$ & $\begin{array}{l}4.7 \pm 1.4 \\
5.8 \pm 1.9\end{array}$ & $\begin{array}{l}0.16 \pm 0.06 \\
0.19 \pm 0.09\end{array}$ \\
\hline \multirow[t]{2}{*}{ C.V. } & Dry & 1.5 & 65 & 75 & 21 & 200 \\
\hline & Wet & 9.6 & 270 & 218 & 52 & 110 \\
\hline $\mathrm{CCME}^{* *}$ & $\begin{array}{l}\text { LEL } \\
\text { SEL }\end{array}$ & $\begin{array}{c}0.60 \\
10.00\end{array}$ & $\begin{array}{c}16 \\
110\end{array}$ & $\begin{array}{c}31 \\
250\end{array}$ & $\begin{array}{l}16.0 \\
75.0\end{array}$ & $\begin{array}{l}120 \\
820\end{array}$ \\
\hline C.B. PECs & & 4.98 & 149 & 128 & 48.6 & 459 \\
\hline
\end{tabular}

Concentrations are mean of triplicate analysis. Values in parenthesis are results of the wet season

C.V: Coefficient of variation; *: Reference location;

C.B PEC: Consensus based probable effect concentrations (above which harmful effects are likely to be observed) (MacDonald et al., 2000).

**: Canadian Council of Ministers of the Environment Guidelines for the Protection of Aquatic Life, 2002

$\beta$ : Recommended guidelines $(\mu \mathrm{g} / \mathrm{L})$ concentration for marine waters. This is the concentration which should not be exceeded for the protection of aquatic ecosystem, 1997

Means in the same column followed by the same superscript are not significantly different $(\alpha=0.05)$ according to Duncan's New Multiple Range Test.

Table 4: Seasonal Correlation Matrix of Metals with some Controlling Factors

\begin{tabular}{|c|c|c|c|c|c|c|c|c|c|}
\hline & Cd & $\mathrm{Cu}$ & $\mathbf{P b}$ & $\mathrm{Ni}$ & Zn & pH & Clay & OC & CEC \\
\hline Cd & 1 & .375 & .630 & $.771^{*}$ & .467 & $.725^{*}$ & $.821^{*}$ & -.526 & $-.786^{*}$ \\
\hline $\mathrm{Cu}$ & .468 & 1 & .499 & .759 & .616 & .247 & .553 & -.696 & -.720 \\
\hline $\mathbf{P b}$ & .678 & .687 & 1 & .641 & .182 & .100 & $.905^{* *}$ & -.175 & -.369 \\
\hline $\mathbf{N i}$ & $.896^{* *}$ & $.760^{*}$ & $.890^{* *}$ & 1 & $.742^{*}$ & .630 & .700 & -.649 & -.773 \\
\hline Zn & .661 & .380 & .358 & .600 & 1 & .597 & .253 & -.659 & -.684 \\
\hline pH & $.813^{*}$ & .044 & .249 & .534 & .536 & 1 & .400 & -.608 & -.702 \\
\hline Clay & $.749^{*}$ & .539 & $.949^{* *}$ & $.869^{* *}$ & .445 & .400 & 1 & -.394 & -.641 \\
\hline OC & -.647 & -.519 & -.274 & -.583 & -.468 & -.608 & -.394 & 1 & $.859^{* * *}$ \\
\hline CEC & $-.786^{*}$ & -.643 & -.561 & $-.795^{*}$ & -.699 & -.702 & -.641 & $.859^{* * *}$ & 1 \\
\hline
\end{tabular}

Significant $/ r / *(P<0.05) ; * *(P<0.01$. $)$ Correlation data for the dry season are placed above the diagonal.

Wet and dry season Pearson coefficients are shown above and below the diagonal line respectively(correlated values are in bold form)

* Corresponding author: ${ }^{1}$ Ololade I.A. 


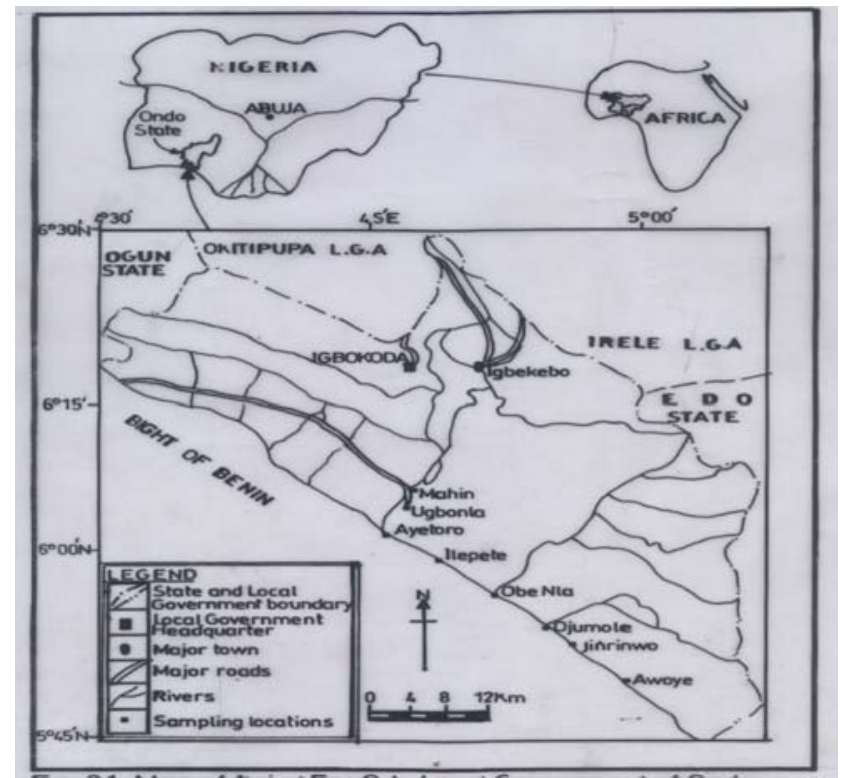

Fig.1. Map of the sampling locations (Inserted is the area map of Nigeria and Africa showing the geographycal locations)

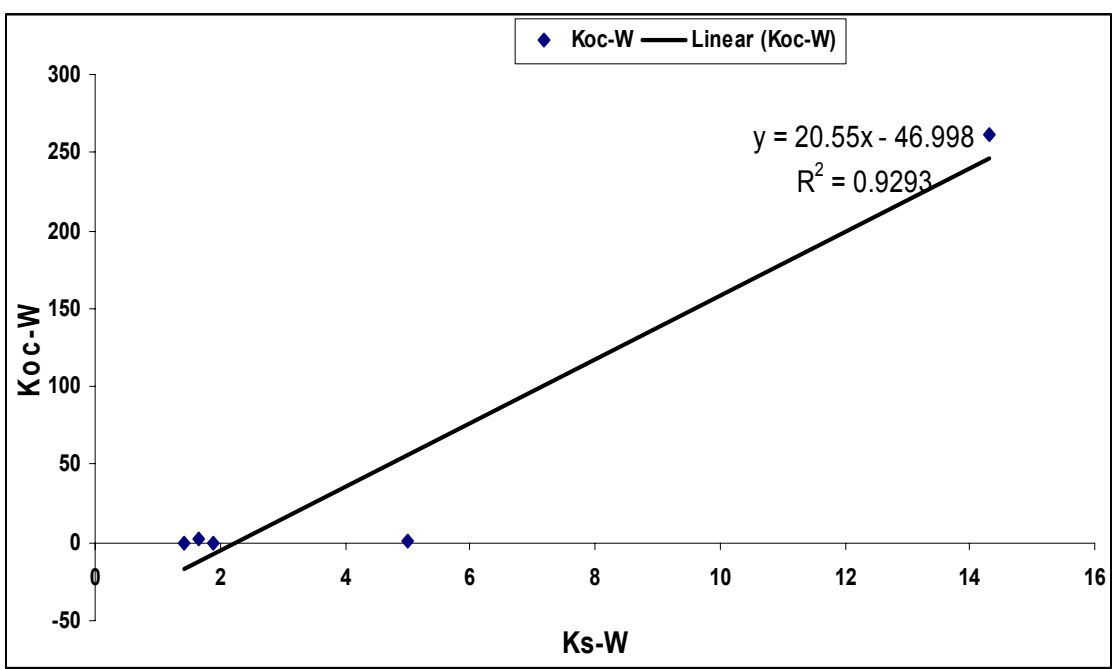

Fig.2-a: Variation of Equilibrium Coefficient during the Wet Season (W = Wet season)

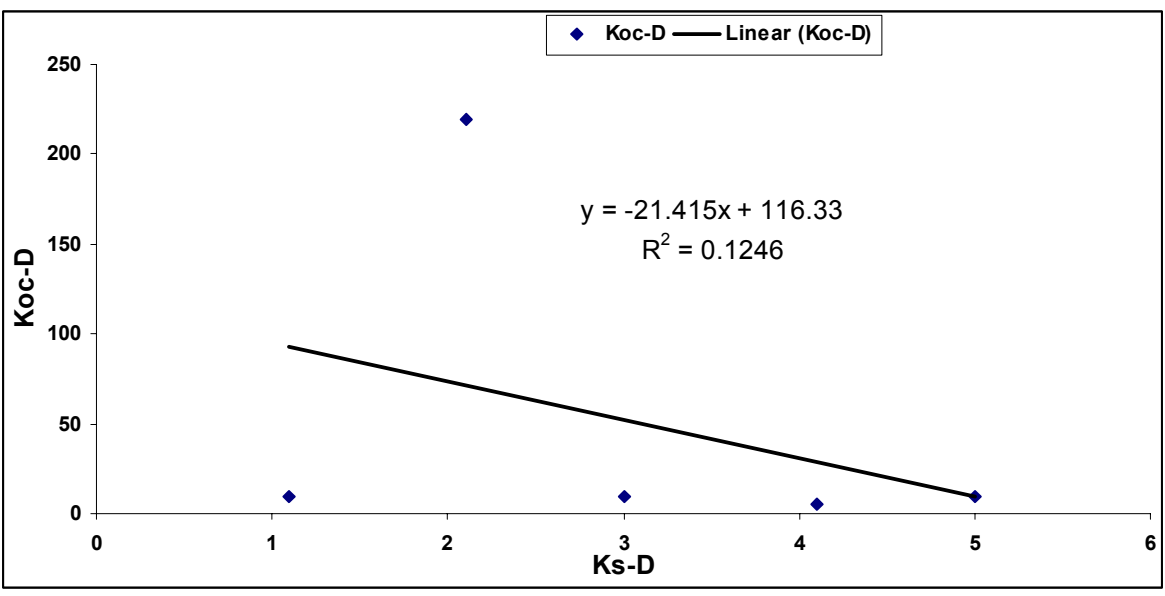

Fig.2-b:Variation of Equilibrium Coefficient during the Dry Season $(\mathrm{D}=$ dry season) 
The sediment water-partition coefficient, Ks, were observed to be greater than the organic carbon partition coefficient, Koc, in three of the metals at both seasons with an order of decreasing adsorption as $\mathrm{Ni}>\mathrm{Cd}>\mathrm{Zn}$. For $\mathrm{Pb}$, the $\mathrm{Ks}$ was greater during the wet season. This again implicates the presence of more $\mathrm{Pb}$ in the aqueous media during the dry season, a factor that may be attributed to the oil spillage that occurred just before the dry season sampling. However, for $\mathrm{Cu}, \mathrm{K} \mathrm{oc}$, were at higher level than $\mathrm{Ks}$ at both seasons. These finding imply that the tendency of the metals to be adsorbed unto the entire sediment particle is a function of several factors such as the characteristics of the metal, the physical and chemical nature of the sediment and possibly some molecular factors contributing to retention. Fig 2(a,b) are displays of the equilibrium partition coefficient variation at both seasons. In the wet season, significant positive correlation $\left(\mathrm{R}^{2}=0.9624\right)$ was observed between the two partition coefficient, Ks and Koc, which can be interpreted to mean a balance flow of ions or particulates within the aqueous medium. The reverse is the case during the dry season $\left(\mathrm{R}^{2}=\right.$ 0.1256 ) and may be attributed to decreased movement and water wave during the period. The $\mathrm{Cu}$ as observed in this report must have been adsorbed unto the humic material (humus). In the hydrosphere, humic material typically makes up about $50 \%$ of the dissolved organic matter. From this limited information, it can be inferred that less fulvic acid and more of humic acid (solubility determinant) are present within the humic component of the sediment matrices. The humic material when bound to mineral phases usually forms coatings which prevent the release of metals into aqueous solution. The results in Table 3, where $\mathrm{Cu}$ was recorded at very high levels, when compared with Ks and Koc values showed that their presence could probably be due to lithological source. This is because humic material is a naturally occurring organic matter of plants and microbial origin.

The concentrations of the metals in the sediment are compared with the consensus based probable effect concentrations and the Canadian Council of Minister of the Environment (CCME) for the protection of aquatic life. These guidelines relate to the potential impact of contaminant on biota, and are derived from analyses of relationship between benthic community health and sediment metal concentrations. Two guidelines are given; the lowest effect level, (LEL) or interim sediment quality guidelines (ISQG), which represent concentration contaminant below which there is a very low probability of effects on the biota and the severe effect levels or probable effect level (PEL) which represent concentrations above which there is a high $(>50 \%)$ probability of adverse effect on the biota.

Based on the limited available data (Table 3), all the sites had sediment concentrations of $\mathrm{Cu}$ far above SEL at both sapling seasons. This is a clear case of sediment heavily enriched with $\mathrm{Cu}$ and its associated toxic nature. However, it is unlikely that this is the result of pollution, as the concentrations of the other metal contaminants were relatively low. The excessively high level of $\mathrm{Cu}$ may be due to mineralogical occurrence. Cadmium did not exceed the SEL in any of the sediment but did exceed the LEL for all sites except for the reference location. The increased level of $\mathrm{Cd}$ in wet over the dry season couples with the concentration above the LEL calls for proper monitoring because of the possibility of greater concentration in the near future over the SEL. Lead exceeded the LEL at only one of the location $\left(\mathrm{S}_{6}\right)$. This may be due to the closeness of this location to oil wells.

Conclusion: It is to be noted that the coastal area of Ondo state is a representative of a typical oil- producing areas in Nigeria and its vicinity are a popular place for recreation (fishing, hunting and boating). The levels of the metals obtained showed that the area is heavily enriched with $\mathrm{Cu}$, the occurrence of which was associated to lithological processes. Cadmium and lead levels in sediment may equally pose serious threat to the area in the near future based on the present concentrations. This region has also been imparted by oil and gas exploration. It is possible that any or all these activities could have contributed to contaminant input. We recommend that cautionary measure, such as prevention of oil spillages into the river, must be enforced to prevent any further increase in metals concentration in the environment. In addition, metals speciation should be carried out so that the form and extent of metal bioavailability can be evaluated further.

\section{REFERENCES}

Adriano, D.C., Bolan, N.J., Vangronsveld, J \& Wenzel, W.W. (2005). Heavy metals. In: D. Hillel. (2nd Ed), Encyclopedia of soils in the environment, (pp 175 - 182). Elsevier, Amsterdam.

Aiken., J.R.(1985). Humic substances in soils, sediments and water. Geochemistry, isolation and characteristics. John Wiley and Sons, New York, 
Asaolu, S.S. (1998). Chemical pollution studies of coastal waters of Ondo State. Unpublished doctoral dissertation, Federal University of Technology, Akure, Nigeria.

Bonnevie, N.L., Huntley, S. L., Found, B.W \& Wenning, R.J.(1994). The metal contamination in surficial sediments from Newark Bay, New Jersey. Sci. Total Environ 144 (1-3), 116.

Boulding, J.R .(1994). Description and Sampling of contaminated soils (A field guide), (2nd ed.) Lewis Publisher, Boca Raton, Florida, USA.

Canadian Council of Ministers of the Environment (CCME) (2002). Canadian sediment quality guidelines for the protection of aquatic life. Winnipeg. Ottawa, Canada, 2002.

Eric Heinen De, C., Michael, S.T \& Stephen, S.A. (2005). Trace elements in streambed sediments of small subtropical streams on Oahu, Hawaii: Results from the USGS NAWQA programme. Appl. Geochem. 20, 2157- 2188 .

Garbarino, J.R., Snyder-Conn, E., Leiker, T.J \& Hoffman, G.L.(2002). Contaminants in Arctic snow collected over northwest Alaskan sea ice water, Air, Soil Pollut. 139, 183 - 214.

Gary, W.V \& Stephen, J.D.(2001). Environmental Chemistry: a global perspective(1ST ed.) Oxford University press, New York.

Karageorgis, A.P., Anagnostou, C.L \& Kaberi, D. (2005). Geochemistry and mineralogy of the NW Aegean Sea surface sediments: Implications for river runoff and anthropogenic impact. Appl. Geochem. 20, 69-88.

Kishe, M.A \& Machiwa, J.F.(2003). Distribution of heavy metals in sediments of Mwanza Gulf of lake victoria, Tanzania. Environ. Intern. 28, 619625 .

Lau, S.S., Chu, L.M. (2000). The significance of sediment contamination in a coastal wetland, Hong Kong, China. Wat. Res. 34 (2), 379-386.

MacDonald, D.D., Ingersoll, C.G \& Berger, T .A. (2000). Development and evaluation of consensus-based sediment quality guidelines for freshwater ecosystem. Arch. Environ Contamn Toxicol, 39,20-31.

Naidu, A.S., Goering, J.J., Kelly, J.J \& Venkatesan, M.I. (2001). Historical changes in trace metals and hydrocarbons in the inner shelf, Beau fort sea: Prior and subsequent to petroleumrelated industrial development. Final report. OCS study MMS 2001-061, University of Alaska Coastal Marine Institute, Alaska. OCS region, $\mathrm{SQ}$.

Nelson, P.W \& Sommers, C.E.(1982). Total carbon, organic carbon and organic matter. In A.L Page, (2nd Ed), Methods of soil analysis ( pp. 539 579), Winconson, USA

Ondo State Environmental Protection Agency, ODSEPA.(2000). Report from the alleged crude oil spill on Ondo coastal waters from Chevron Nig. Ltd Ewan Production Platform. Ministry of Environment, Ondo State, Nigeria, July 12 .

Page A.L., Miller, R.H., Keeney, D.R (eds.) (1982). Methods of soil analysis, part 2 Chemical and microbiological properties (2nd ed.). Soil Science Society of America: Madison.

Pekey, H., Karakas, D., Ayberk, S., Tolun, L \& Bakolu. M. (2004). Ecological risk assessment using trace elements from surface of Izmit Bay (Northeastern Marmara sea),Turkey. Mar. pollut. Bull. 48, 946-953.

Polemio, M \& Rhoades, J.D.(1977). Determining cation exchange capacity: A new procedure for calcareous and gypsiferous soils. Soil Sci. Soc. Am. J. 41, $524-528$.

Schollenberger, C .J. (1945). Determination of carbonates in soil. Soil Sci., 59, 57-63

Singh, A.P \& Srivastava, P.C. (2008). Relationship of heavy metals in natural lakes water with physico-chemical characteristics of waters and different chemical fractions of metals in sediments. Water, Air Soil Pollut, 188, 181-193. DOI 10.1007/s11270-007-9534-6.

Snyder-Conn, E., Garbarino, J.R., Hoffman, G.L \& Oelkers, A.(1997). Soluble trace elements and total mercury in arctic Alaskan snow. Arctic, 50, $201-215$

Thomas, L.P \& Kathleen, E.S. (1998). Composition of petroleum mixtures: Total petroleum hydrocarbon criteria working group series, Vol 2 (pp.2-8), Amherst Scientific Publishers, Massachusetts.

Woitke, P., Wellmitz, J., Helm, D., Kube, P., Lepom, P \& Litheraty, P. (2003 Analysis and

* Corresponding author: ${ }^{1}$ Ololade I.A. 
assessment of heavy metal pollution in suspended solids and sediments of the river Danube. Chemosphere 51, 633-642.
Wakeman, T.H., Themelis, N.J (2001). A basin wide approach to dredged material management in New York/New Jersey Harbor. J. Hazard Mat. 85, 1-13. 